\title{
O brincar criativo e a obesidade infantil
}

\author{
Fernanda Kimie Tavares Mishima \\ Valéria Barbieri \\ Universidade de São Paulo
}

\begin{abstract}
Resumo
A obesidade infantil é uma das doenças mais preocupantes atualmente, o estudo de seus fatores psicológicos é escasso, podendo se vincular a características específicas do brincar. Este trabalho objetiva investigar se há algum prejuízo causado pela dificuldade de expressão da criatividade no brincar de crianças obesas e, em caso positivo, qual a sua natureza. Foram realizados cinco estudos de caso com meninos obesos entre 7 e 10 anos, de nível sócio-econômico médio e famílias intactas, com aplicação do Teste do Desenho da Figura Humana (DFH) e Teste de Apercepção Temática Infantil (CAT-A). Observou-se que a dificuldade das crianças em criar, simbolizar e brincar gerava sentimento de solidão e abandono. As figuras parentais foram vistas como ambivalentes, não suprindo as necessidades afetivas e a dependência dos filhos, mas exigindo sua autonomia. $\mathrm{O}$ comer compulsivo apresentou-se como única maneira de interagir com o ambiente, preenchendo a privação afetiva experienciada nas relações precoces.
\end{abstract}

Palavras-chave: obesidade; brincar; crianças; técnicas projetivas; criatividade.

\begin{abstract}
Creative playing and the childhood obesit. Childhood obesity is one of the most preoccupying actual disorders. The study of its psychological factors is scarce; however, it may be associated to specific characteristics of playing. The present study aimed to investigate if there is any damage related to the difficulty of expressing creativity in obese children's playing, and, if so, its characteristics. Five case studies had been carried with between 7-10-year-old obese boys of average socioeconomic level and intact families. Two psychological tests were applied, the Draw-a-Person Test (DAP) and the CAT-A. The results suggested children's difficulties in creating, symbolizing and playing, leading to a feeling of solitude and abandonment. The parental figures had been seen as ambivalent and not able to satisfy children's needs and dependence, but demanding their autonomy, tough. Compulsory eating was presented as the only way to interact with the environment, by filling the affective privation experienced in precocious relations.
\end{abstract}

Keywords: obesity; playing; children; projective techniques; creativity.

$\mathrm{E}$ studos têm demonstrado que a obesidade é causada por múltiplos fatores, há poucas pesquisas que tratam dos aspectos psicológicos envolvidos em sua etiologia, predominando estudos sobre as causas orgânicas (genéticas, biológicas e funcionais) da doença e os efeitos que ela acarreta na vida das pessoas. Assim, apesar do aumento do impacto global da obesidade na saúde pública, não há acompanhamento na mesma proporção por investigações sobre esse problema, principalmente no que se refere à magnitude dessa epidemia em pessoas jovens.

No Brasil, de acordo com últimos dados da Associação Brasileira para o Estudo da Obesidade (ABESO), aproximadamente $40 \%$ dos brasileiros são obesos ou estão acima do peso (Fisberg, 2005). Ao comparar as estatísticas dos anos de 1974/75 e 1989, notou-se um aumento de sobrepeso e obesidade de $53 \%$, e, caso esse ritmo permaneça, Coutinho (1999) prevê que na primeira metade do terceiro milênio todos os brasileiros poderão se tornar obesos. Com relação às crianças, segundo dados publicados na Pesquisa Nacional sobre Saúde e Nutrição (PNSN) há uma prevalência de 7\% de obesidade nos meninos e $9 \%$ nas meninas brasileiras (Taddei, 1993). Em determinadas localidades, os índices inspiram preocupação: na Bahia há 9,3\% de crianças com sobrepeso e 4,4\% com obesidade (Oliveira, Cerqueira, \& Oliveira, 2003); em São Paulo há 2,5\% de obesidade em crianças menores de 10 anos entre as classes econômicas menos favorecidas, e 10,6\% na mais favorecida (Monteiro, Mondini, Souza, \& Popkin, 1995); na cidade de Recife o sobrepeso e a obesidade atingem cerca de $30 \%$ das crianças e adolescentes (Balaban \& Silva, 2001).

Fisberg (2005) afirma que são fatores determinantes para a obesidade infantil: peso gestacional, desmame precoce, introdução inadequada de alimentos complementares, emprego de fórmulas lácteas inadequadamente preparadas, distúrbios do comportamento alimentar e má relação familiar. Quanto ao 
adolescente, é necessário acrescentar as modificações do período de transição para a idade adulta, baixa auto-estima, sedentarismo, lanche excessivamente mal balanceado e grande aceitação da propaganda consumista, fatores que também não deixam de estar presentes na vida da criança.

A obesidade provoca efeitos psicológicos na criança deixando marcas durante toda sua existência. A dificuldade nos esportes, apelidos, zombarias dos amigos, vergonha de se desnudar perante os outros promove sentimentos de inferiorização e desprezo por si mesmo (Schwartz \& Puhl, 2003).

Características como imaturidade, dependência, passividade e baixa auto-estima podem ser consideradas atributos psicológicos de crianças obesas (Ades \& Kerbauy, 2002; Banis, Varni \& Wallander, 1988). Para Loke (2002) essas características se articulam na dinâmica psicossocial da criança e promovem sentimentos como aumento da tristeza, solidão e nervosismo.

Aspectos psicológicos acompanham a obesidade infantil e os estudos relatam predominantemente as conseqüências psíquicas advindas dessa patologia. É comum alguns pacientes adultos, particularmente aqueles com obesidade mórbida, optarem por ficar longe do convívio social, isolarem-se em suas casas na presença da família e de escassos amigos, tudo para se protegerem de agressões verbais e não verbais (Lemes, 2005). Além da dificuldade enfrentada devido ao preconceito e discriminação sofridos no ambiente escolar e profissional, o obeso também se depara com aquelas advindas do ambiente familiar, na forma como são vistos e tratados.

Essas considerações sustentam, de forma unânime, que a obesidade acarreta dificuldades tanto para a saúde física quanto para a mental, não importando a idade do indivíduo. Nesse sentido, não é possível compreender seus fatores etiológicos de forma isolada, já que eles agem de maneira conjunta e se refletem em todos os aspectos da vida do indivíduo. Neste ponto, é fundamental considerar a importância da família, tanto como apoio no tratamento do obeso como, muitas vezes, atuante na etiologia de sua doença.

Levantamento bibliográfico realizado na base de dados Medline, Capes e Lilacs, no período de 1980-2008, com as palavras-chaves "obesity", "childhood obesity", "childhood obesity and psychology" e "childhood obesity and family", mostrou que dentre os fatores ambientais relacionados à obesidade, os mais considerados são os de natureza sóciocultural, como etnia, ambiente, mito da beleza, que alinhados a pesquisas com população de adultos obesos enfatizando a origem física e biológica da obesidade, dominam a literatura. Há pequena quantidade de estudos envolvendo o papel dos aspectos psicológicos, particularmente aqueles vinculados à situação familiar na etiologia da obesidade, o que sugere certa negligência ao tema. Em contrapartida, há vários estudos que informam sobre o tratamento e prevenção da doença, incluindo o papel da família nesse processo, mas meramente quanto aos fatores genéticos e à influência do comportamento alimentar dos pais, em detrimento das características psicodinâmicas familiares relacionadas à sua origem.

Em vista do alarmante aumento da prevalência dessa doença, de suas graves conseqüências e da escassez de pesquisas referentes aos aspectos psicológicos nela envolvidos, este estudo tenciona compreender o funcionamento psicodinâmico de crianças obesas, salientando a ligação emocional entre mãe e filho, de modo a contribuir para uma abordagem dessa patologia que seja ao mesmo tempo mais ampla e mais precisa.

Spada (2005) afirma que a obesidade exógena pode ser decorrente de dificuldades afetivas que vêm do vínculo mãe/filho. Como essas dificuldades são impedidas de serem transformadas, mais bem elaboradas, contidas, simbolizadas e representadas na mente, elas são manifestadas através do corpo. A atitude de ingerir alimentos como conseqüência de uma privação ambiental também foi salientada por Christoffel e Forsyth (1989) e por Felliti (1993).

Winnicott (1964/1982) enfatiza as seguintes situações em que a presença da mãe é necessária e as condições em que ela deve ocorrer:

1) nas necessidades psicológicas e emocionais da criança por meio do atendimento às necessidades físicas, a mãe deve aparecer como pessoa viva nessa situação;

2) na apresentação do mundo ao bebê: com o conhecido processo de ilusão (a criança crê que pode criar o seio quando está com fome), para que ele acredite que o mundo pode conter o que é querido e necessário, dando-lhe esperança de que há uma relação viva entre a realidade interior e a exterior, entre a capacidade criadora inata, primária, e o mundo compartilhado por todos;

3) na desilusão: após ter iludido seu bebê, de maneira gradual, a mãe o leva a aceitar que, mesmo que o mundo forneça algo parecido com aquilo que ele busca e que pode ser criado, não o fará de maneira automática, nem na hora exata em que ele sente o desejo.

Quando a mãe está presente (física e psicologicamente) nessas situações é definida por Winnicott (1958/2000, 1964/1982) como suficientemente boa, ou seja, capaz de oferecer holding para a criança, cuidar e confortar no momento adequado. Se ela é suficientemente boa, a criança passa a ser capaz de criar um mundo interior e pessoal, que se relaciona com o mundo exterior e compartilhado.

Dias (2003) afirma que nenhuma criança é capaz de se tornar uma pessoa real se não estiver sob os cuidados de um ambiente que ofereça sustentação e facilite os processos de amadurecimento emocional. Portanto, o que existe é o indivíduo em relação ao mundo externo; primeiramente, há a relação de um par corporal e depois entre unidades corporais.

Por meio das brincadeiras, as crianças estabelecem uma forma de contato com o mundo interno e externo, com interação entre eles. Desse modo, Winnicott (1964/1982) afirma que se a criança brinca sozinha ou acompanhada é sinal de que não há nenhum problema aparentemente grave, já que o brincar, possibilitado por um ambiente razoavelmente bom e estável, revela que ela é capaz de desenvolver um modo de vida pessoal e se transformar em um ser humano integral.

Portanto, é de grande relevância para a vida da criança e seu futuro que ela saiba e consiga brincar. Para tanto, é necessário que ela se identifique com um lar e com um ambiente emocional adequados e estáveis. É preciso que os pais dêem amor a seus filhos, que os vejam como pessoas totais para que eles 
desenvolvam uma personalidade rica e equilibrada, para que consigam se adaptar ao mundo. Contudo, mesmo quando as experiências iniciais são boas, aquilo que foi conquistado precisa ser consolidado no decorrer do tempo (Winnicott, 1964/1982).

Pensando nas formas possíveis de brincar, Winnicott (1964/1982) ressalta que, além do brincar por prazer, as crianças brincam para dominar suas angústias, ou seja, para controlar as idéias ou impulsos. Quando há ameaça de um excesso de angústia, o brincar se torna compulsivo ou repetitivo, ou, ainda, a criança busca exageradamente os prazeres da brincadeira. Assim, se a angústia é muito grande, o brincar acaba se transformando em pura exploração da gratificação sensorial, e não em uma atitude propriamente feliz. Nesse caso, as únicas maneiras de relação com o exterior são o fazer e o ter, como o ato de comprar, consumir e comer como formas de preencher o vazio angustiante, o sentimento de solidão e acalmar a sensação de ansiedade intolerável (Abadi, 1995/1998). Nesse mesmo sentido, Mc Dougall (1984/1999) afirma que para preencher a falta da mãe introjetada que cuida, o obeso busca no mundo externo um substituto, como o objeto de adicção (comida). Assim, todo afeto ameaçador será descarregado no comportamento aditivo. Contudo, como essa falta não é reparada, dá-se início a uma busca compulsiva desse objeto; portanto, a solução do obeso está relacionada a um duplo projeto narcísico: reparar um ego danificado e manter a ilusão de onipotência através da comida.

Por outro lado, a criança que se identifica com um lar e ambiente emocional bons e estáveis apresenta desenvolvimento emocional saudável, ou seja, consegue brincar de maneira construtiva e ter uma atitude feliz. Com isso, ela adquire experiência através da brincadeira, sua personalidade se desenvolve e se enriquece por meio das invenções do brincar; ela aumenta sua capacidade de enriquecer o mundo real através da possibilidade de simbolizar e conviver socialmente. Dito de outra forma, o brincar proporciona uma organização inicial para estabelecer as relações emocionais e propicia o desenvolvimento de contatos sociais, um sentimento de que pertence ao mundo (Winnicott, 1971/1975, 1964/1982). Desse modo, o brincar auxilia no processo de unificação e integração social da personalidade, ou seja, serve como ligação entre a relação do indivíduo com a realidade interior e a relação com a realidade externa ou compartilhada (Winnicott, 1964/1982).

Portanto, o brincar construtivo advém da experiência de passar pelo espaço transicional, espaço intermediário que representa o início das relações com o mundo e das relações da criança com uma pessoa total. Representa a transição da criança de um estado de fusão com a mãe para um estado de relacionamento com a mãe como algo externo e separado, como representa o encontro entre o mundo psíquico e o mundo socialmente construído (Winnicott, 1964/1982, 1958/2000).

Se a mãe está ausente por um período longo demais, o espaço transicional perde seu valor e sua função. Consequentemente, a criança parte para atividades excitantes, pois se perdeu a área intermediária de contato afetivo. Essa situação se agrava ainda mais quando a criança se sente abandonada e se torna incapaz de brincar, de ser afetuosa ou aceitar uma afeição. Elas acabam por apresentar dificuldades de simbolizar e de criar.

Franco (2003) assinala que o verdadeiro brincar infantil não é um brincar fingido, artificial e sem implicações, mas sim uma preocupação e compromisso com os elementos da brincadeira. Winnicott (1964/1982), por sua vez, assinala que é no brincar e somente no brincar que o ser humano pode ser criativo e usar toda sua personalidade. É por meio da criatividade que ele descobre o eu - self. Isso ocorre porque, ao vivenciar o espaço transicional, a criança consegue fazer uso de determinado objeto de maneira pessoal. O brincar, ou seja, a aceitação de símbolos, possibilita à criança experimentar aquilo que está presente em sua íntima realidade psíquica pessoal, base do crescente sentido de identidade.

Neste ponto, é importante ressaltar que somente o ser verdadeiro, o self, tem possibilidades de se sentir real, o que permite ao indivíduo adquirir, ao longo da vida, um mundo interior original e pessoal, que represente seu estilo de ser pessoal (Safra, 2005). Assim, os indivíduos que não puderam ter experiências que lhes dessem um sentido para o self, não sentem que podem ter fecundidade no mundo, que podem ter uma ação e transformá-lo de forma pessoal. Eles vivem uma impotência básica, uma castração do ser.

Sendo assim, nota-se que é de suma importância o papel do ambiente que circunda a criança, formado pelas figuras parentais e outras pessoas do convívio da mesma. É esse ambiente que oferece possibilidades para a criança desenvolver seu self, passar do período da ilusão para o da desilusão, fazer uso de objetos transicionais como forma de entrar em contato com o ambiente e consigo mesma.

Assim, tendo em vista o exposto alhures, o objetivo deste estudo foi investigar a expressão de criatividade da criança obesa e o que esta aponta sobre sua relação com sua família à luz da Teoria Winnicottiana.

\section{Método}

Este estudo foi realizado por meio do método do estudo de caso coletivo (Stake, 2000), com aplicação de técnicas projetivas e sua associação com a maneira de brincar da criança e a expressão de sua criatividade. Participaram cinco crianças obesas de 7 a 10 anos do sexo masculino, com IMC-por-idade $\geq 95 \%$, de nível sócio-econômico médio e de famílias intactas: Tiago $^{1}$ (7 anos), Antônio (9 anos), Joaquim (8 anos), Hugo (7 anos) e Marcelo (10 anos). Foram escolhidos meninos devido à escassez de estudos com crianças desse gênero. Foram encaminhados por um médico pediatra, após avaliação física, a fim de detectar componentes orgânicos, funcionais e genéticos relativos à obesidade. Para selecioná-las, foram excluídas as crianças com suspeita de comprometimento intelectual ou antecedentes psiquiátricos, bem como anormalidade física.

Após o consentimento dos pais e da assinatura do Termo de Consentimento Livre e Esclarecido, foi feita uma sessão com os pais, para realizar uma entrevista semi-estruturada, abordando a história de vida dos filhos. Depois, foram feitas duas sessões individuais com as crianças, com aplicação da técnica projetiva do Desenho da Figura Humana (DFH) de Machover (1949) para avaliação da personalidade, especificamente no que tange à imagem corporal, e do Teste de Apercepção Temática Infantil - forma animal (CAT-A), avaliado segundo referencial 
de Bellak e Bellak (2000) para aprofundar a avaliação da personalidade, no que se refere à qualidade dos objetos internos e das relações familiares. Todas as sessões ocorreram em consultório particular.

Ao final, procedeu-se o processo de qualificação, comparação e análise dos dados, avaliados de forma descritiva. Os dados advindos da entrevista foram abordados qualitativamente, caracterizando a amostra quanto à história de vida, história da alimentação e peso e relatos de doenças físicas e emocionais. Os dados relativos ao Desenho da Figura Humana (DFH) e CAT-A foram descritos e interpretados em relação às características da imagem corporal e objetos internos, natureza do superego, controle pulsional e relacionamento familiar, conforme procedimento da livre inspeção (Trinca, 1984), segundo referencial psicanalítico winnicottiano. Apesar da singularidade de cada caso, houve semelhanças entre eles e os dados são descritos de maneira conjunta.

\section{Resultados}

A análise qualitativa da entrevista, do CAT-A e do DFH indicou que todas as crianças apresentaram sinais de dificuldade no processo criativo. Elas se mostraram presas ao concreto, com prejuízo em brincar de uma maneira criativa e espontânea, em que pudessem mostrar seu estilo de ser pessoal. A dificuldade no processo criativo pode ser vista por alguns sinais durante a realização do CAT-A: bloqueio inicial para inventar estórias, ausência de sentimentos dos personagens, recorrência comum em descrever a figura. Tais indícios podem ser ilustrados pelo relato de Hugo na lâmina VIII: "Uma turma de macaco. Uma turma de macacos sentada no sofá (...) uma mulher. [e aí, que mais?] Só. E tá um retrato de uma macaca. Só. É só”; e pelo de Tiago, na lâmina VI: "Essa é igual dos três ursos. Já passou na tv, três ursos dormindo, um ficou de fora, não foi dormir com os outros... mas aconteceu igual dos três ursos. [o que aconteceu?] Eu já contei” (refere-se à estória da lâmina II).

As crianças se identificaram principalmente com a figura masculina: sexo masculino desenhado em primeiro lugar no DFH e heróis também masculinos no CAT-A. Contudo, no CAT-A prevaleceram características negativas dos protagonistas, como passividade, medo, maldade e voracidade; já nos desenhos, houve sinais de insegurança, baixa auto-estima, inferioridade e dificuldade no contato com os outros, especialmente por serem desenhos representados em tamanho pequeno, com traços interrompidos e mãos desproporcionais.

Nas estórias do CAT-A apareceram temas semelhantes, como roubo, agressividade, medo, solidão e atitudes de muita passividade, como se a angústia tomasse conta da criança, mobilizasse e paralisasse a busca de solução para o conflito. $\mathrm{O}$ tema da punição foi recorrente, como ilustrado na estória de Tiago (lâmina X): "O filhinho ficou doente e o pai deu uma surra nele de dor na bunda. Aí ele pulou na privada, molhou o pai e o pai ficou bravo... ele tava sentindo muita dor de bunda, levou uma surra". Nesse sentido, a família apareceu nos temas sem características de acolhimento ou fornecimento de holding, mas como punitiva, que não permite a expressão pessoal.

O distanciamento afetivo ficou marcado nos relatos da entrevista com os pais, quando estes se referiam ao momento da amamentação: a mãe de Antônio disse que não pôde amamentálo no peito porque não teve leite, e mesmo a amamentação na mamadeira foi delegada ao pai; a mãe de Joaquim contou que o filho dormia nessa hora, acordava e chorava quando o peito era tirado, sem haver uma comunicação entre mãe e filho; a mãe de Tiago relatou que ela própria dormia quando amamentava, correndo o risco de cair do sofá onde estava com ele; já a mãe de Hugo disse que tinha leite para amamentar, mas, às vezes, quando chegava a hora, ficava nervosa porque tinha que deixar o que estava fazendo e, depois de um tempo, não agüentava mais alimentar o filho. Esses fatos sugerem uma dificuldade de doação da mãe no momento de amamentar, passível de dificultar o contato com o filho, a transmissão de segurança e de confiança.

Todas as crianças apresentaram indícios de uma figura materna controladora e de pouco afeto, que era capaz de suprir as necessidades concretas (físicas), mas não as afetivas, o que pode ser observado pela inadequação do afeto ilustrada na estória contada por Tiago na lâmina II: "Era uma vez três ursos, eles começaram a comer a sopa que a mãe fez, a do pai tava muito quente, a do menino tava muito gelada, a da mãe tava muito mole"; ou ainda na contada por Antônio, na mesma lâmina: "A mãe deles chega, fala para eles arrumá a mesa pra ela fazer a janta pra eles comerem. Ela fala pra eles virem pra mesa, primeiro lavá a mão antes de vir na mesa e fala pra eles serem educados, e pra agradecer a comida que eles tem e comerem".

Nesse contexto, os desenhos das crianças também sugeriram ambivalência entre a autonomia e o desejo de ser cuidado, de ser criança. Houve sinais de que tiveram que crescer antes da hora, assumir responsabilidade antes do tempo, o que pode ter proporcionado uma falsa adaptação ao mundo externo e às exigências do meio, gerando sentimento de solidão, conforme as estórias contadas na lâmina I, por Antonio e Marcelo, em que falavam da responsabilidade de não se sujar e ter higiene.

Para Marcelo, a figura materna transmitia uma mensagem ambígua, isto é, ao mesmo tempo em que mostrava desejo de que o filho fosse independente, não queria livrá-lo da dependência em relação a ela. Assim, nem supria a dependência, nem desiludia o filho, indicando dificuldades no momento de estabelecer a ilusão/desilusão e de atender às necessidades das crianças (não oferecia holding para que o filho se sentisse seguro): lâmina IX "Um dia num quarto bem escuro, bem lá no fundo tinha uma coelhinha que queria dormir em paz (...). O maior medo dela era o escuro, então pra ela conseguir dormir sempre tinha uma luz acesa. A mãe dela falou: 'minha filha, apague essa luz que você dorme', e a menina: 'mas eu tenho medo' (...) A mãe fala: 'o que eu faço então?', 'Vem você dormir aqui e eu aí', 'mas aí seu pai vai te chutar a noite inteira', a mãe diz. Aí a menina fala: 'põe o colchão aí do lado e eu durmo, mas tem que ter luz acesa'. A mãe responde: 'aí eu não aceito'. (...) e então cada uma fica no seu quarto".

A carência do bom ambiente também pode ser observada nas seguintes estórias do CAT-A: Antônio na lâmina VI: “(...) foram dormir em sua toca, que era uma caverna cheia de flores e bastante escura"; Joaquim na lâmina VIII: "Era uma vez uma casa de macacos, tinha filho, pai, vó, vô e também tinha muito 
retrato, ficava um fedor dentro daquela casa. Não tinha ninguém que lavava".

Os relatos das crianças indicam que suas mães não puderam oferecer-lhes uma experiência afetiva que possibilitasse estabelecer um vínculo pessoal com o mundo e, com isso, a integração da criatividade primária com a realidade objetiva do meio. Consequentemente, o brincar mostrou-se comprometido, com prejuízos na espontaneidade da criança e em sua relação com o ambiente externo.

Os desenhos das crianças indicaram que, diante da dificuldade de integrar as realidades externa e interna, o ambiente era visto como tendo uma existência concreta, que não fazia parte do mundo interno da criança, era 'acoplado' e superposto ao self. Dessa forma, houve indícios de funcionamento falso self em três das crianças deste estudo (Tiago, Antônio, Marcelo), confirmado pelo concretismo das estórias do CAT-A, que denunciava a dificuldade de criar.

Nas estórias, as principais necessidades dos heróis foram as de proteção reclamada, afiliação emocional, nutrição e agressão em relação ao meio, sugerindo busca do concreto (alimento) como forma de abrandar as angústias e preencher a lacuna afetiva, mas em uma ação descoordenada em relação ao meio externo, como se vê nos relatos de Hugo na lâmina I: "Eles tá comendo comida... (...) [que que eles tão sentindo?] vontade de chantili. [e o que fazem?] vai pegar e comer", e também na estória de Joaquim na lâmina V: "Urso de pelúcia. Os ursinho ganhou vida e começaram a brigar dentro do berço (...) A mãe taca os urso no lixo e ficam felizes para sempre". Neste último trecho, é possível assinalar a pouca capacidade da mãe em compreender o filho e ajudá-lo no manejo da própria agressividade.

A figura do pai foi vista exercendo um controle baseado na autoridade pura, desvinculada do afeto (superego primitivo, mas não protetor), o que acarreta sentimento de abandono, medo e não pertencimento familiar:

- "O rei leão estava fumando o seu cachimbo, de repente chegou um rato, derrubou o seu cachimbo [que o rei faz?]. (...) Ficou zangado. E aí no final o rei catou ele e o comeu" (Joaquim, lâmina III);

- "Eles começam a correr. E entram dentro dessa casa, e o filhinho dele fica pra trás" (Joaquim, lâmina IV);

- "Era uma vez muitos animais da espécie, o rei Leão encontrou uma leoa e casou com ela, e teve um filho, o filho era parecido com um macaco" (Tiago, lâmina III).

Os dados do DFH e do CAT-A, particularmente referentes à maneira como as crianças percebem seu ambiente familiar e como reagem a ele (busca de soluções mágicas, descoordenadas, permeadas por atitudes impulsivas), indicam que há alto nível de ansiedade, fazendo com que elas recorram a algo concreto do ambiente a fim de amenizar a angústia. Portanto, o prejuízo gerado na doação afetiva leva a uma busca por alimento como forma de abrandar a falta, pois as crianças sentem não poder contar com a família para suprir suas necessidades afetivas e receber holding. Esse sentimento de abandono e solidão faz com que elas busquem no alimento uma forma de completude, uma maneira de acalmar a angústia, como no caso de Antônio na lâmina VI: "O ursinho voltou e a mãe ficou muito brava porque ele saiu sem sua mãe deixar. E o ursinho começou a comer as maçãs".

Dessa forma, é possível inferir que as crianças obesas desse estudo, na tentativa de controlarem o excesso de angústia, brincam de uma maneira compulsiva e repetitiva, buscando a pura exploração da gratificação sensorial, sem apresentarem uma atitude propriamente feliz. A única forma de se relacionar com o externo é o ter, para preencher o vazio angustiante, o sentimento de solidão e acalmar a sensação de ansiedade intolerável. Contudo, é importante destacar que algum grau de simbolização foi atingido, já que as crianças foram capazes, em algum grau, de contar estórias, mesmo que relacionadas às próprias vivências concretas.

\section{Discussão}

Em consonância a pesquisas realizadas anteriormente (Ades \& Kerbauy, 2002; Banis, Varni, \& Wallander, 1988), as crianças obesas deste estudo apresentaram características como dependência, passividade e baixa auto-estima, além de sinais de timidez, insegurança, vergonha, crença de que eram diferentes e sentimentos de incapacidade e desmotivação.

Em relação ao ambiente familiar, as crianças apresentaram vontade de serem independentes, porém com incapacidade para se desvencilhar do objeto de dependência que não era satisfatório para elas (não supria suas necessidades). Dessa forma, sentiam-se inseguras, sozinhas e desprovidas de apoio.

As experiências de deficiência do holding exercido pelas mães acabaram por levar a prejuízos na transicionalidade e, consequentemente, na capacidade de simbolização, com apego ao objeto concreto, no caso o alimento, e com comprometimento da criatividade e do brincar espontâneo. $\mathrm{O}$ brincar se mostrou mais como uma possibilidade de dramatização da angústia que permanece presente do que como área de experimentação. Portanto, o brincar das crianças obesas desse estudo não parece ir além da função catártica e, assim, não cria espaço para a experiência cultural.

A busca excessiva das crianças por alimento pode ser considerada um sintoma de grande ansiedade, sugerindo dificuldades psíquicas, afetivas e relacionais. Dessa forma, a ingestão de alimentos pode se constituir numa tentativa de superar a dor mental e preencher a falta do objeto materno introjetado que cuida (Mc Dougall, 1984/1999), consequência de uma privação no provimento das necessidades infantis. Portanto, este estudo subsidia as conclusões de Fisberg (2005), de que as raízes psicológicas da obesidade infantil remetem às falhas estruturais da relação mãe/filho.

Desse modo, a raiz mais primitiva das dificuldades das crianças deste estudo encontra-se na fase de dependência relativa (Winnicott, 1958/2000), em que não houve suficiente provento das necessidades de ilusão devido ao holding insuficiente, o que resultou em prejuízo em sua adaptabilidade, no conhecimento de seu mundo interno, no desenvolvimento de seu sentido de self e na expressão de sua criatividade (Winnicott, 1971/1975). Consequentemente, as crianças buscaram fazer uso de um objeto que preenchesse a lacuna afetiva experienciada no processo de ilusão-desilusão, e o objeto escolhido foi o alimento. Contudo, 
essa lacuna não parece ter sido absoluta, mas vivida no contexto de um movimento inconstante das mães, que iludiam de forma deficiente, desiludiam, voltavam a iludir de modo insuficiente e desiludiam novamente.

Dito de maneira mais específica, as crianças, ao vivenciarem o processo de ilusão - desilusão, tiveram uma figura materna que possibilitou, até certo ponto, a crença de serem capazes de criar um objeto, porém, ao desiludir, fizeram-no de forma muito brusca, retirando subitamente todo o apoio e satisfação das necessidades. Posteriormente, voltaram a iludir a criança, para depois novamente interromperem a ilusão de maneira brusca. Essa experiência produziu na criança uma dificuldade de vivenciar a experiência de frustração da onipotência, levando a prejuízos na passagem pela transicionalidade e na capacidade de simbolização, que foi alcançada somente de forma parcial (nenhuma criança foi diagnosticada como psicótica).

Como o objeto transicional representa o contato entre a psique e a realidade (Winnicott, 1971/1975), quando há prejuízos na experiência nessa área, há danos para o desenvolvimento do self verdadeiro, e, dessa forma, a alternativa perante a dificuldade de existir passa a ser o reagir (Winnicott, 1958/2000).

Como as crianças obesas deste estudo parecem ter alcançado a área transicional apenas parcialmente, pode ter ocorrido a cronificação patológica do objeto transicional ou fetichização do objeto (Abadi, 1995/1998).

Em suma, as crianças obesas deste estudo parecem não ter tido experiências que lhes dessem um sentido para o self, passando a acreditar que não podiam ter ação e transformação no mundo, que não podiam modificá-lo de maneira pessoal (Safra, 2005). Como uma das formas de expressão dessa maneira pessoal é o brincar, ele se mostrou comprometido nas crianças, principalmente pelo prejuízo no processo de completude da simbolização, advindo das dificuldades na relação mãe-filho durante o estágio de dependência. Nesse caso, o brincar parece ser compulsivo, ou seja, como busca no ambiente de uma maneira de gratificação sensorial (pulsional) e não uma forma de expressão espontânea de felicidade. Ao brincar, as crianças demonstraram estar presas a objetos concretos, mas esses objetos não pareciam fazer parte de seu self, pareciam estar soltos, sobrepostos a ele. É como se elas não tivessem tido a oportunidade de senti-los como seus, identificá-los, introjetá-los, para depois se darem conta de que fazem parte do mundo externo, e então se desfazerem deles após tê-los integrado a si mesmas; somente dessa forma é que o brincar acontece de maneira espontânea e criativa.

Em função dessa dificuldade, é possível assinalar que as crianças não foram capazes de fazer uso do objeto apropriandose dele de maneira pessoal e criativa, mas sim limitada pela gratificação momentânea por ele proporcionada. Como não ocorreu a incorporação de fato do afeto, devido aos problemas na transicionalidade, que impediram o introjetar pleno do objeto, o preenchimento do vazio falha e a criança permanece em um círculo vicioso: alimento - busca por afeto - vazio - alimento.

Apesar da insuficiente provisão ambiental, as crianças conseguiram atingir o estágio de dependência relativa e a capacidade de simbolização, mas ainda de uma maneira incompleta. Com isso, poucos recursos secundários são usados e desenvolvidos, as crianças agem no mundo movidas pela pulsão, com pouca intermediação pelo pensamento (acting-out), o que acarreta ansiedade, intenso sentimento de culpa e crença de que merecem punição e castigo pela expressão dos impulsos. Isso faz com que as crianças se sintam inseguras, inferiores, não pertencentes ao meio familiar, causando mais ansiedade e novamente a busca por comida.

\section{Considerações Finais}

As crianças obesas demonstraram dificuldade em criar, em brincar, em deixar sua imaginação fluir. Esse prejuízo parece ter sido causado pela presença de uma família que não foi vista como acolhedora, que cuida, capaz de suprir afetivamente, mas como uma família formada por pais que usam de autoridade para dominar o filho, que tentam suprir as carências concretas (alimento) em detrimento das afetivas. Assim, não atenderam a dependência dos filhos para que eles fossem capazes de ter autonomia e segurança, mas os desiludiam precocemente, prejudicando a capacidade de criar.

A busca por alimento pareceu ocorrer como forma de preencher o vazio que ficou durante o processo de ilusãodesilusão, quando não tiveram apoio afetivo e holding suficientes para que pudessem ser desiludidas gradualmente e viver plenamente as experiências da área transicional. A ação das crianças no mundo é concreta, movida pela ansiedade, que gera intenso sentimento de culpa. Elas se sentem inseguras, inferiores, não pertencentes ao meio familiar, características que geram mais ansiedade, levando-as a buscar novamente a comida. Dessa forma, pode-se considerar que tais características psicológicas aparecem como fatores coadjuvantes na etiologia da obesidade.

Diante dessas considerações acerca do conhecimento psicodinâmico da criança obesa, destaca-se que o trabalho psicoterapêutico envolvendo essa patologia precisa abranger a recuperação da capacidade criativa, vista como a possibilidade de estar no mundo, de se sentir real e capaz de articular experiências em símbolos do self. É um trabalho de introdução destes símbolos no espaço potencial (transicional), local de junção da experiência de ser, que irá inscrever o self do indivíduo no campo cultural. O trabalho terapêutico implicaria na construção de uma relação que permita o reconhecimento de si e do outro, a possibilidade de brincar e criar. Esse processo além de ser visto como importante no tratamento da obesidade, também se mostra relevante para o desenvolvimento emocional posterior do indivíduo, a fim de amenizar as conseqüências psíquicas e o preconceito vivenciado por essas crianças quando se tornam adultos obesos.

\section{Referências}

Abadi, S. (1998). Transições: o modelo terapêutico de D. W. Winnicott. (L. Y. Massuh, Trad.). São Paulo: Casa do Psicólogo. (Publicado originalmente em 1995)

Ades, L., \& Kerbauy, R. R. (2002). Obesidade: realidades e indagações. Psicologia USP, 13(1), 197-216.

Balaban, G., \& Silva, G. A. P. (2001). Prevalência de sobrepeso e obesidade em crianças e adolescentes de uma escola da rede privada de Recife. Jornal de 
Pediatria, 77, 96-100

Banis, H. T., Varni, J. W., \& Wallander, J. L. (1988). Psychological and social adjustment of obese children and their families. Child Care Health \& Development, 14, 157-173.

Bellak, L., \& Bellak, S. S. (2000). Teste de apercepção infantil: com figuras de animais - CAT-A. (M. T. A. Pacheco, Trad.). São Paulo: Livro Pleno.

Christoffel, K. K., \& Forsyth, B. W. C. (1989). Mirror image of environmental deprivation: severe childhood obesity of psychological origin. Child Abuse and Neglect, 13, 249-256.

Coutinho, W. (1999). Consenso latino-americano de obesidade. Arquivos Brasileiros de Endocrinologia e Metabologia, 43(1), 21-67.

Dias, E. O. (2003). A Teoria do Amadurecimento de D. W. Winnicott. Rio de Janeiro: Imago.

Felliti, V. J. (1993). Childhood sexual abuse, depression, and family dysfunction in adult obese patients. Southern Medical Journal, 86, 732-736.

Fisberg, M. (2005). Primeiras palavras: uma introdução ao problema do peso excessivo. In M. Fisberg (Org.), Atualização em obesidade na infância e adolescência (pp. 1-10). São Paulo: Editora Atheneu.

Franco, S. G. (2003). O brincar e a experiência analítica. Ágora, 6(1), 45-59.

Lemes, S. O. (2005). Acompanhamento emocional da obesidade na infância e adolescência. In M. Fisberg (Org.), Atualização em obesidade na infância e adolescência (pp. 95-106). São Paulo: Atheneu.

Loke, K. Y. (2002). Consequences of childhood and adolescent obesity. Asia Pacific Journal of Clinical Nutrition, 11(3), S702-S704.

Machover, K. (1949). Personality profection in the drawing of the human figure.
Springfield: Charles C. Thomas.

Mc Dougall, J. (1999). Psicanalistas de hoje. São Paulo: Via Lettera. (Publicado originalmente em 1984)

Monteiro, C. A., Mondini, L., Souza, A. L., \& Popkin, B. M. (1995). The nutrition transition in Brazil. European Journal of Clinical Nutrition, 49, 105-113.

Oliveira, A. M. A., Cerqueira, E. M. M., \& Oliveira, A. C. (2003). Prevalência de sobrepeso e obesidade infantil na cidade de Feira de Santana-BA: detecção na família x diagnóstico clínico. Journal of Pediatric, 74(4), 325-328.

Safra, G. (2005). A face estética do self: teoria e clínica. São Paulo: Unimarco.

Schwartz, M. B., \& Puhl, R. (2003). Childhood obesity: a societal problem to solve. Obesity Reviews, 4, 57-71.

Spada, P. V. (2005). Obesidade infantil: aspectos emocionais e vínculo mãe/filho. Rio de Janeiro: Revinter.

Stake, R. E. (2000). Case studies. In N. K. Denzin \& Y. S. Lincoln (Orgs.), Handbook of Qualitative Research Thousand Oaks (pp. 435-454). London: Sage Publications.

Taddei, J. A. A. (1993). Epidemiologia da obesidade na infância. Pediatria Moderna, 29(2), 111-115.

Trinca, W. (1984). Diagnóstico psicológico: a prática clínica. São Paulo: EPU.

Winnicott, D. W. (1975). O brincar e a realidade (J. O. A. Abreu, Trad.). Rio de Janeiro: Imago. (Publicado originalmente em 1971)

Winnicott, D. W. (1982). A criança e o seu mundo (A. Cabral, Trad.). $6^{\text {a }}$. ed. Rio de Janeiro: Livros Técnicos e Científicos. (Publicado originalmente em 1964)

Winnicott, D. W. (2000). Da pediatria à psicanálise. (D. Bogolometz, Trad.). Rio de Janeiro: Imago. (Publicado originalmente em 1958)

1. Os nomes das crianças foram alterados para preservação do sigilo ético.

Fernanda Kimie Tavares Mishima, Psicóloga Clínica do Centro de Pesquisa e Psicologia Aplicada (CPA) da Faculdade de Filosofia, Ciências e Letras de Ribeirão Preto da Universidade de São Paulo (FFCLRP-USP), é Doutoranda em Psicologia pela Faculdade de Filosofia, Ciências e Letras de Ribeirão Preto da Universidade de São Paulo (FFCLRP-USP).

Endereço para correspondência: Universidade de São Paulo, Faculdade de Filosofia, Ciências e Letras de Ribeirão Preto, "Campus" de Ribeirão Preto, Avenida Bandeirantes, n. 3900

CEP: 14040-901 - Ribeirão Preto - SP. Telefone: (16)3602-3641, Fax: (16)3602-4835

E-mail: fktmishima@ffclrp.usp.br

Valéria Barbieri, Doutora em Psicologia pelo Instituto de Psicologia da Universidade de São Paulo (IP-USP), é professora do Departamento de Psicologia e Educação da Faculdade de Filosofia, Ciências e Letras de Ribeirão Preto da Universidade de São Paulo (FFCLRP-USP)

E-mail: valeriab@ffclrp.usp.br 